\title{
Occupant Comfort and Satisfaction in Green Healthcare Environments: A Survey Study Focusing on Healthcare Staff
}

\author{
Suk-Kyung Kim ${ }^{1}$, Ying Hwang ${ }^{1}$, Young S. Lee ${ }^{1} \&$ William Corser $^{2}$ \\ ${ }^{1}$ Inteiror Design Program, School of Planning, Design, \& Construction, Michigan State University, USA \\ ${ }^{2}$ Institute for Health Policy, College of Human Medicine, Michigan State University, USA \\ Correspondence: Suk-Kyung Kim, School of Planning, Design, \& Construction, Michigan State University, East \\ Lansing, MI 48824, USA. Tel: 1-517-353-9367. E-mail: kimsk@msu.edu
}

Received: October 27, 2014 Accepted: November 21, 2014 Online Published: January 28, 2015

doi:10.5539/jsd.v8n1p156

URL: http://dx.doi.org/10.5539/jsd.v8n1p156

\begin{abstract}
Since the US Green Building Council introduced green building design strategies and measurement indicators as the name of LEED (Leadership in Energy and Environmental Design) in 2000, different rating systems for various types of facilities have been developed. LEED for Healthcare that was initiated to improve healthcare buildings' energy efficiency and sustainability is one of them. Yet, there is still a strong debate over whether LEED certified hospitals provide more comfortable environments for the staff to work in than the counterparts.

The purpose of this study was to identify effective factors influencing healthcare occupants' comfort and satisfactions through comparing the perceptions of the healthcare staff from green hospitals with those from conventional hospitals. The study mainly targeted nursing staff because they spend about eight hours daily in such environment to improve patients' health outcomes. By comparing the perceptions of the healthcare staff from green hospital (or LEED-certified hospitals) and conventional non-LEED-certified hospitals, the results from this study showed significant differences between two types of hospitals studied. This study additionally reviewed these effective elements, examined if they were indoor environmental quality elements or interior design elements, and discussed if green healthcare environments actually contributed toward improving occupant's comfort and satisfaction.
\end{abstract}

Keywords: healthcare facility, LEED, occupant comfort and satisfaction

\section{Introduction}

\subsection{Background}

As buildings consume more than $70 \%$ of the electricity and a large part of materials, water, and generate $60 \%$ of non-industrial waste (National Institute of Building Sciences, 2010), green buildings have become one of the main practices to constrain resource costs. Embracing multiple aspects that surround a building such as site conditions, energy consumption, water efficiency, indoor environmental quality, material uses, innovation in design and regional characteristics, green building is "an integrative effort to transform the way built environments are designed, constructed, and operated"(US Green Building Council (USGBC), 2009). In green buildings, the consumption of energy, water, and other resources are greatly reduced by adopting various methods and energy and water saving technologies (USGBC, 2009). Furthermore, green buildings aim to achieve high performance in human and environmental health via improved occupant productivity and comfort by providing better indoor environmental quality (USGBC, 2011).

Since the US Green Building Council introduced green building design strategies and measurement indicators as the name of LEED (Leadership in Energy and Environmental Design) around in 2000, different rating systems for various types of facilities have been launched (USGBC, 2014). LEED for Healthcare which was established to improve healthcare buildings' energy efficiency and sustainability is one of them. Aligning with an increase in the development of healthcare buildings in the United States due to graying of the baby boom generation and the need to replace aging 1970s hospitals (Ulrich et al., 2008), rehabilitating or newly constructing healthcare facilities into be green has been highlighted. It has thus been popular to design those facilities to achieve certain level of energy- and water-efficiency, site sustainability, and indoor environmental quality. In fact, the number of healthcare facilities to achieve LEED-certifications has been increasing. As of October in 2014, approximately 
220 healthcare facilities applied for LEED for Healthcare certifications. Some of them achieved certifications while others were in the process of application. This showed that the design principles of green building have been adapted to many healthcare facilities (USGBC, 2014).

Generally, indoor environments in green buildings are known to be more comfortable and satisfactory for their occupants than conventional buildings (Lee \& Kim, 2008; USGBC, 2009). Previous studies revealed that the LEED-certified buildings generally provide better indoor air quality, thermal comfort, furnishings, and maintenance than the counterparts. Yet, many studies targeted commercial buildings. It still remains unclear if LEED-certified healthcare facilities provide better indoor and building environments for their occupants.

Because green healthcare designs are increasingly being adopted in practice, it is important to assure this new healthcare design sustainably addresses the needs of the occupants and indeed promote the comfort and satisfaction of the staffs who occupy daily in those facilities. Some previous studies have shown the significant relationships between indoor environmental factors and occupant health and comfort (Lee \& Kim, 2012). However, there are still information gaps to determine that indoor environments in green hospitals provide more comfortable and satisfactory conditions for their occupants compared with conventional ones. Furthermore, there are still unclear if indoor environmental factors in green hospitals positively affect occupant comfort and satisfaction, in particular, to healthcare staffs who are in fact strongly associated with the quality of patient care delivered over time.

\subsection{Purpose of the Study}

The purpose of this study was to identify the environmental factors of green hospitals that affect occupant comfort and satisfaction. This study investigated staff's perceived comfort and satisfaction through questionnaire surveys that determined such environmental factors. To examine staff's comfort and satisfaction in green hospitals and conventional ones, a comparative study was conducted. The research team investigated environmental characteristics of green and conventional hospitals, and examined the impact of environmental elements in those hospitals on staffs' perceived comfort and satisfaction therein. This study delimited the green hospitals to LEED-certified hospitals which meant the Leadership in Energy and Environmental Design certified by U.S. Green Building Council and the conventional hospitals to non-LEED-certified hospitals. To examine the environmental characteristics that can affect occupant comfort and satisfaction, the research team categorized selected environmental features into indoor environmental quality elements and design elements. These elements were discussed more in the Data Collection Method section. This study included a post-occupancy evaluation aspect and suggested better building design considerations for improving comfort and satisfaction of healthcare occupants in their work environments. Five specific research questions were tested to achieve the research purpose. They were:

1) Should healthcare buildings' environmental characteristics (LEED vs. non-LEED) influence the perception of the comfort toward the workplace between the staffs from two healthcare building types? 2) Should the healthcare building designs (LEED vs. non-LEED) influence the satisfaction toward the workplace between the staffs from LEED-certified hospitals and non-LEED-certified hospitals? 3) Should the perception of comfort influence the overall satisfaction toward the workplace among healthcare staffs? 4) Is there a significant relationship between comfort and overall satisfaction, what comfort categories are responsible for the difference in the satisfaction toward the workplace?, and 5) What design considerations should be considered for the future green healthcare designs, based on this study's findings? Since green healthcare designs are increasingly being adopted in practice, it's important to assure this new healthcare design sustainably addresses the needs of the staff.

\section{Literature Review}

Increasing number of studies has been carried out focusing on evaluating the quality of built environments through measuring occupant comfort. There is a growing body of evidence that comfortable indoor environment attributes that include indoor air, thermal comfort, lighting, acoustic, daylight and outdoor views can lead to improvements in productivity in the workforce and hence greater competitiveness for the company involved (Heerwagen, 2000).

Lee and Kim (2008) found occupants in LEED-certified commercial buildings were more satisfied with indoor air, thermal comfort, office furnishings, and cleanliness maintenance than those in non-LEED-certified buildings. Yet, the occupants in LEED-certified buildings were less satisfied with lighting and acoustics with those in non-LEED-certified buildings. These findings revealed that the LEED-certified buildings generally provide better indoor air quality, thermal comfort, furnishings, and maintenance that the counterparts. 
While studies on indoor air quality are far too vast to be covered fully in this paper, the message is very clear: indoor air quality is one of the key factors affecting workers' health, well-being, and perceptions of ambient conditions. For example, results obtained by Hummelgaard et al. (2007) indicated a higher degree of satisfaction and a lower prevalence of Sick Building Symptoms (SBS) among the occupants in the naturally ventilated buildings comparing to mechanically ventilated buildings. In another study of Heerwagen (2000), indoor air quality was greatly improved due to material selection, construction techniques, enhanced ventilation and inclusion of indoor nature settings in green buildings, which suggested green design could possibly improve the occupant comfort as well as satisfaction level. Lee and Guerin (2009) also discovered that there was a positive correlation between indoor air quality and worker performance in green buildings. In a most recent article, the occupant satisfaction level towards their thermal and visual environment was found to be clearly better in a contemporary environmentally-concerned building compared to those in a conventional high-rise office block (Zhang et al., 2011). Humidity is another factor showing a significant effect on the occupant comfort as well as the energy consumption (Simonson, et al., 2002).

There is evidence showing that indoor lighting is also closely related to occupants' comfort levels. Earlier studies showed people valued daylight and preferred to be near windows (Collins, 1975; Heerwagen et al., 1986). Literature regarding occupant preferences and satisfaction with the luminous environment and control systems in day lit offices were reviewed by Galasiu et al (2006) which showed a consistent strong preference for daylight. In green building designs, daylight has been used as the primary light source that reduces building energy demand and at the same time enhances indoor environment quality (see USGBC, 2009).

A recent study showed generally high satisfaction was perceived with daylight work environment in a LEED gold-certified laboratory building (Hua et al., 2010). On the other hand, as it's still necessary to have artificial lighting, energy efficient, high quality electric lighting not only to reduce energy consumption, but also reduces computer glare, increases visual comfort, and adds an aesthetic element that is good for the mood of the occupants. These features have been commonly used in green buildings which have been found to reduce headache, eyestrains, and can serve as a buffer to discomfort or work-related stresses (Boyce, 1998).

Moreover, it has been demonstrated that being able to have visual contact with nature through window views, sitting in the sun or shade, and walking in interior streets with natural settings can enhance occupants' mood and promotes higher quality of life (Heerwagen, 2000). A study examining the effects of window view on perception of spaciousness, brightness and room satisfaction in a campus building revealed that rooms with open and natural window views at higher levels were perceived larger and rated more satisfied by the occupants (Ozdemir, 2010). A view of natural elements was also found to buffer the negative impact of job stress on intention to quit and to have a similar elect on general well-being (Leather et al., 1998).

Noise is another indoor environmental contributor that greatly affects occupant comfort. It has been proved that noisy environments are stressful, frustrating and prevent people from doing their job to the best of their abilities (Bordass, 2000). Satisfaction was found to drop significantly with increasing noise, as revealed in a field study assessing disturbance by the study of Sundstrom et al (1994) that surveyed 3391 employees at 58 sites. Negative effects of acoustic environment increased stress significantly, including augmented distraction, reduced privacy, and increased concentration difficulties and use of coping strategies. Acoustic quality has been found to be problematic in many green buildings including LEED-certified buildings in the early green building practice (Lee, 2011; Lee \& Guerin, 2009; US Green Building Council Chicago Chapter, 2009). Strategies have been developed to reduce noise in green building design (De Salis et al., 2002; Swift et al., 2008) and LEED standard for indoor acoustical quality has been proposed (Jensen et al., 2008).

Thermal comfort has been shown to correlate strongly with perceived comfort of the workplace (Roulet et al., 2006; Xie et al., 2009). The results of overheating in summer, under-heating in winder, and excessive variability of temperature could be detrimental to the occupants' comfort (Edwards, 2006). In fact, a study conducted in Australia (Paul \& Taylor, 2008) showed that people staying in a green library in summer perceived the indoor environment as warmer and less comfortable. This shows a potential issue of green buildings associated with thermal comfort caused by saving energy for heating and cooling.

The studies reviewed thus far, however, were all conducted for non-healthcare buildings. In the healthcare industry, a number of studies have demonstrated that staff, especially nurses, experience higher levels of work stress, which were found to contribute to nurse burnout and an intention to leave one's current job (Billeter-Koponen et al., 2005; Scully, 1980; Sharma et al., 2008; Ulrich et al., 2008). However, only a few studies have explored how the built environment contributes to the comfort and satisfaction of healthcare staff that include nurses and therapists' in their work environments. 
Regarding indoor air quality, Jiang et al. (2003) found that good ventilation could significantly reduce the viral load of the hospital ward and might be the key to prevent outbreaks of severe acute respiratory syndrome (SARS) among healthcare workers. Two other studies conducted by Smedbold et al. (2002), and Menzie et al. (2000) both found significant decrease in illness infection among healthcare staff was related to less fungus in the air with better ventilation supply. In addition, Cooper-Marcus and Barnes (1995) found that many nurses and other healthcare workers used the gardens for achieving pleasant escape and recuperation from stress. There is also evidence that healthcare staff perceive higher sound levels generated by the equipment as stressful (Bayo \& Garcia, 1995; Norbeck, 1985). Noise-induced stress in nurses also correlates with reported emotional exhaustion or burnout (Topf \& Dillon, 1988). A study conducted by Blomkvist et al. (2004) also found lower noise levels were linked with a number of positive effects on staff such as improved quality of care for patients. Finally, a large scale study conducted by Buchanan et al. (1991) examined a correlation between the appropriate lighting level and reduction of medication dispensing error rates. They found that medication dispensing error rates were significantly lower at an illumination level of 1,500 lux (2.6\%) than those of 450 lux (3.8\%).

These previous studies have confirmed the significant relationships between healthcare staffs' satisfactions and important environmental elements such as ventilation, garden, noise, and lighting level. Some of the studies also examined certain environmental characteristics between green and conventional healthcare facilities and the effects of environments on occupants. However, there have been few studies that identified diverse indoor environmental characteristics both in green and conventional hospitals to examine the effects of these environmental characteristics on hospital occupants in a comprehensive manner, in particularly to healthcare staffs. Ideally, developing an improved understanding of environmental factors in this area could help improve the quality of patient care delivered over time.

\section{Methodology}

\subsection{Research Settings}

Data were collected from the staff of the chosen healthcare facilities. Two groups of hospitals, one for the green hospital group and the other for the conventional hospital group were compared in regard to the similarity and differences between staff comfort and satisfaction in the two groups of buildings. For the green hospital group, two LEED-certified hospitals were selected and for the conventional hospital group, one non-LEED-certified hospital which did not even attempt a LEED certification. This non-LEED certified hospital partially updated their systems or equipment but had kept their original building designs. The LEED-certified facility conditions were of equivalent age to the non-LEED-certified buildings.

After sending mails several times to recruit participating hospitals, the research team included three hospitals: two LEED-certified hospitals and one non-LEED-certified hospital located in Michigan. Each hospital has major characteristics as follows. Figures 1-4 show interior characteristics of green hospitals

\subsubsection{Green Hospitals (LEED-certified Hospitals)}

\subsubsection{M Health Hospital}

This hospital was located in Wyoming in Michigan. It was certified by LEED from the U.S. Green Building Council in 2009. In this hospital, water-conserving fixtures, including waterless urinals and low-flow faucets had been adopted to reduce the use of water. Fabrics, furniture, paints, adhesives, sealants and carpets with low volatile organic compounds (VOCs) and low emissions were used to help maintain indoor air quality. Environmental friendly cups, compostable plates and glasses were used in the cafeteria. Motion-sensitive lights and natural lighting were incorporated to conserve energy. Instead of a traditional roof, the 48,000-square-foot roof of the hospital's main building is covered by living plants, which required less maintenance, provides greater insulation and offers a more therapeutic environment for patients.

\subsubsection{B Cancer Center}

This cancer center is located on the north side of Grand River in Farmington Hills, MI, opened in January 2009. It's the first LEED silver-certified cancer center in Michigan. In this hospital, landscaped open space comprised more than $20 \%$ of the site. Portable water use had been reduced by $28.7 \%$ by installing low-flow lavatories, kitchen sinks and exam sinks as well as dual-flush toilets. About $21.3 \%$ of the building materials were manufactured using recycled substances. More than $20 \%$ of the building materials were comprised of components extracted, harvested, recovered or manufactured within 500 miles of the site. The lighting design in the entire site reduced light pollution significantly and natural light was maximized for interior spaces. The minimum oxygenated air quantities supplied to the site's HVAC equipment exceeds LEED's requirement. An air filtration system had been installed, capturing about $80 \%$ of 1 -micron particles at maximum dust loading, which 
expects to improve indoor air quality.

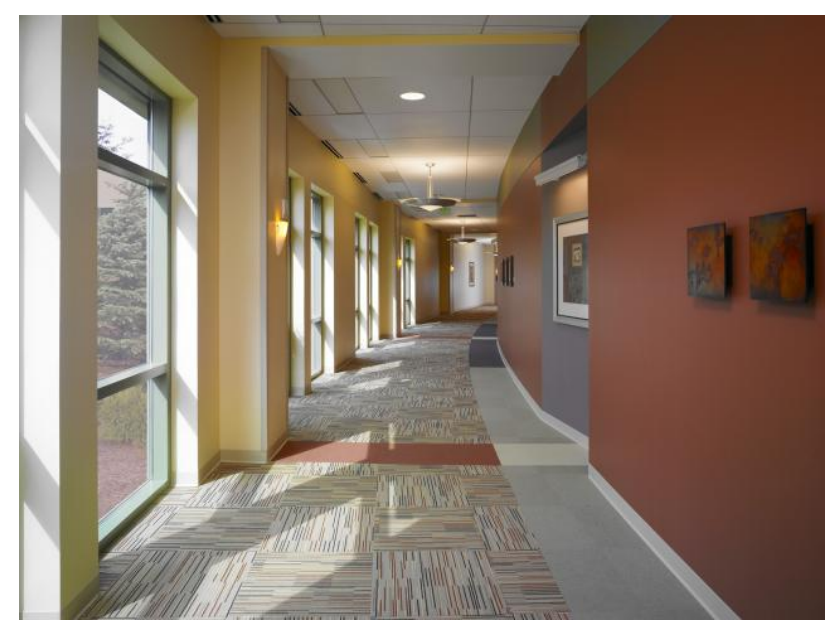

Figure 1. Interior space of M health hospital using low emission materials and paints

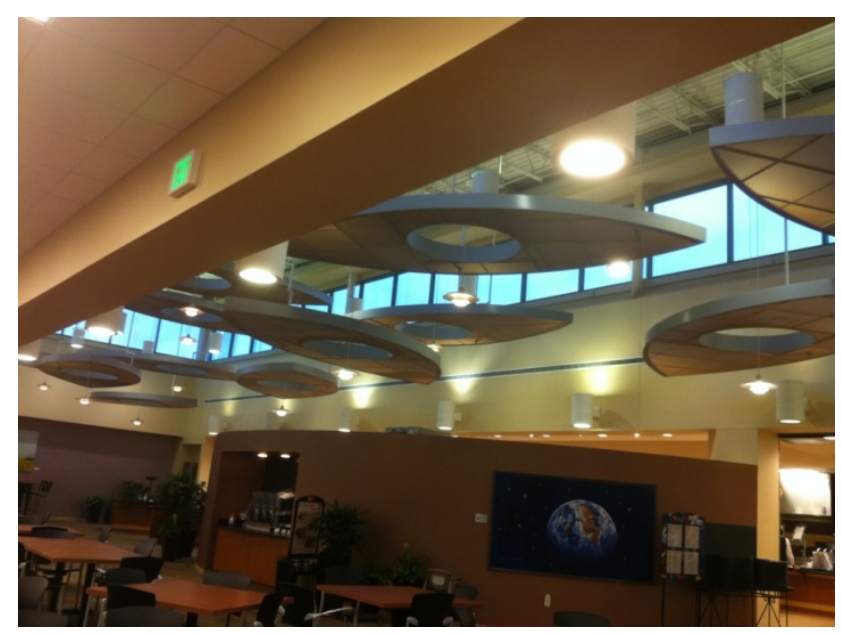

Figure 2. Cafeteria in $M$ health hospital showing the use of natural light

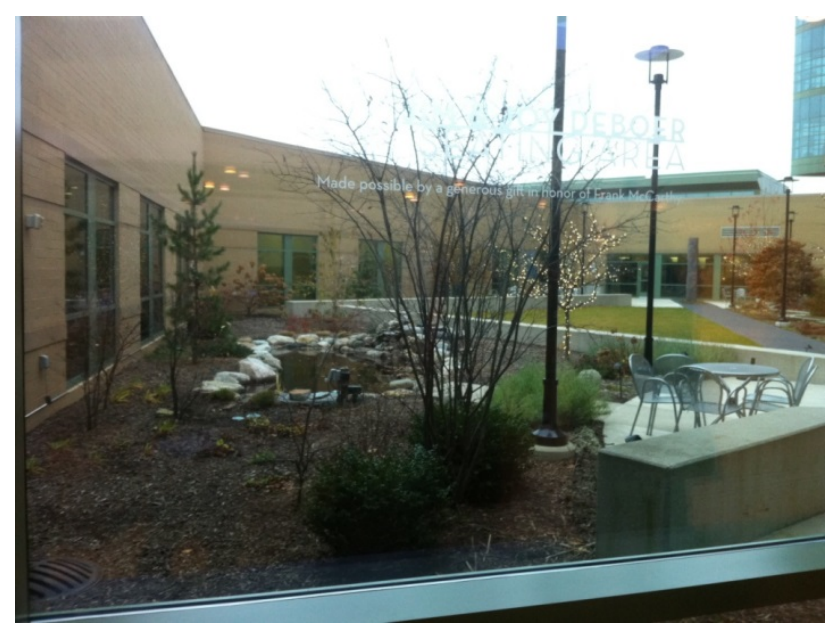

Figure 3. Outdoor lounge in M health hospital 


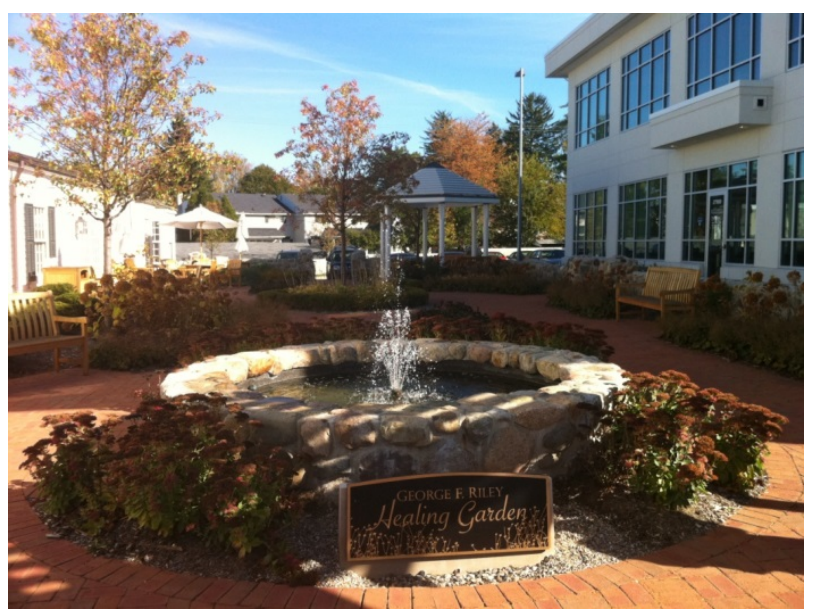

Figure 4. Outdoor lounge with a healing garden in B cancer center (All image credits by authors)

\subsubsection{A Conventional Hospital: B Hospital Main Campus}

This hospital is located on Grand River Avenue in Farmington Hills, founded in 1965. It was a 330-bed health care facility serving communities in the southeast Michigan area. In 2009, there were totally around 2,500 employees including more than 600 medical staff.

In this hospital, no energy-saving or water-saving features had been implemented. Conventional HVAC systems were installed to provide ventilation and to regulate indoor temperature and humidity. Artificial lighting was mainly used in all buildings with limited introduction of natural lighting. There was no rain garden or outdoor lounge at this campus. The first author could locate no documentation indicating that the original materials used in this hospital had been environmentally conscious.

\subsection{Data Collection Methods and Respondents}

The questionnaire used to measure perceived comfort and satisfaction of healthcare staffs consisted of four sections. It was developed based on the previous research related to occupant comfort and satisfaction in the work environment (Heerwagen, 2000; Lee \& Kim, 2008; Paul \& Taylor, 2008; Veitch et al., 1998) and employee satisfaction questionnaire developed by Gastle (2006). Part 1 asked questions about the general information of the participants including age, gender, type of work and years worked. Part 2 asked the participants to rate their perception of the working conditions with regard to comfort on a seven-point scale. The survey examined the workspace conditions in terms of hospital layout, wayfinding and signing system, materials and color, lighting, noise, ventilation, indoor natural settings, temperature, humidity, and outdoor lounge. These ten items for examining occupants' comfort were categorized into two groups to examine whether green building features driven by a LEED certification could positively affect occupant comfort. The two categories were indoor environmental quality elements (i.e., temperature, humidity, noise, ventilation, and lighting) and design elements (i.e., hospital layout, wayfinding and signing system, materials and color, indoor natural settings, and outdoor lounge). The indoor environmental quality elements were created based on the categories presented by U.S. Green Building Council (2009). In general, LEED rating systems consist of sustainable sites, water efficiency, energy and atmosphere, materials and resources, and indoor environmental quality as baseline categories. Indoor environmental quality includes thermal comfort, indoor air quality, acoustics, and lighting (USGBC, 2009). This study therefore included temperature, humidity, noise, lighting, and ventilation as indoor environmental quality elements. Part 3 asked the participants seven questions about their perceived satisfaction. Part 4 asked a series of open questions to capture any important facts relevant to the purpose of the study.

Prior to the data collection, the questionnaire had been reviewed and approved by the Institutional Review Boards of the Human Subject Protection Program at Michigan State University and IRB committees at the selected hospitals. The questionnaire surveys were administered on-site at the three subject hospitals. Researchers visited the hospitals based upon their permission and administered the survey questionnaire to individual healthcare staff members at the end of the staff meeting and collected their completed questionnaires. To increase the number of responses, researchers visited the target facilities more than three times and collected the surveys from the voluntary participants. The survey began in November 2010 and completed in February 
2011. Finally, the research team collected 54 responses from LEED-certified hospitals and 25 from a conventional non-LEED certified hospital.

\subsection{Data Analysis Plan}

\subsubsection{A Comparison of Occupant Comfort Perception between Building Types}

As previously mentioned, ten categories were used to measure various aspects of perceived comfort. They were temperature, humidity, noise, ventilation, and lighting which belonged to indoor environmental quality elements, and hospital layout, wayfinding and signing system, materials and color, indoor natural settings, and outdoor lounge which were defined as design elements.

The mean for each category was calculated for LEED and non-LEED-certified hospitals and was compared using mean difference tests. The purpose of this test was to examine if there was significant difference in each of the perceived comfort category between two building groups (or building types). This test also examined whether occupant comfort was affected by green building features or design features of healthcare environments.

\subsubsection{A Comparison of Occupant Satisfaction between Building Types}

There were seven questions to evaluate the occupant satisfaction. Table 3 shows these seven questions. The mean for each question was calculated and compared for different building types using mean difference tests. Because the staff satisfaction toward the working environment in two building groups could have been influenced by factors other than the existence or absence of green building attributes such as workload, type of work, and interpersonal relationship, these questions could help identifying the satisfaction related to building types from those which are not. Then the responses for those satisfaction questions showing clear difference between green and non-green hospitals were summed and averaged to result in a new overall satisfaction parameter labeled as "overall satisfaction." The purpose of this test was to determine if the overall perceived satisfaction was associated with two groups (green vs. conventional building occupants).

\subsubsection{Correlation between Perceived Comfort and Overall Satisfaction}

Statistical relationship between overall satisfaction and ten comfort categories were calculated for both green and conventional hospitals using Pearson's correlation coefficients. To identify the comfort categories that influence perceived satisfaction, a simple linear regression analysis was then additionally performed to determine the degree of the effect for each comfort category on overall satisfaction. The regression test results showed whether occupants' comfort and satisfaction in their current work environments were significantly influenced by green building features or not.

\section{Findings and Discussion}

\subsection{Demographic Characteristics of Respondents}

Participants of this research were mainly healthcare staff members. Among the respondents from LEED-certified hospitals, $16.7 \%$ were nurses, $66.7 \%$ were therapists, $11.1 \%$ were administrators, and $5.6 \%$ were physicians. Half of the participants were older than 40 years of age and approximately $68 \%$ were females. Among the respondents from the non-LEED certified hospital, $80.0 \%$ were nurses, $8.0 \%$ were therapists, and $12.0 \%$ were administrators and there was no physician. All participants were older than 40 years of age, and more than $90 \%$ were females. The green building group had more therapists and the conventional building group had more nurses. However, their work environments such as exam rooms and offices were similar, thus the effect of demographic differences between the two groups on the results were assumed to be minimal. Table 1 shows these characteristics of respondents. 
Table 1. General characteristics of respondents

\begin{tabular}{rrrrrrrr}
\hline & & \multicolumn{2}{c}{ LEED certified } & \multicolumn{2}{c}{ Conventional } & \multicolumn{2}{c}{ Total } \\
\cline { 3 - 8 } Job type & frequency & $\%$ & frequency & $\%$ & frequency & $\%$ \\
& Physician & 3 & 5.6 & 0 & 0.0 & 3 & 3.8 \\
& Nurse & 9 & 16.7 & 20 & 80.0 & 29 & 36.7 \\
& Therapists & 36 & 66.7 & 2 & 8.0 & 38 & 48.1 \\
& Administrator & 6 & 11.1 & 3 & 12.0 & 9 & 11.4 \\
& Total & 54 & 100.0 & 25 & 100.0 & 79 & 100.0 \\
& Ange & 27 & 50.0 & 0 & 0.0 & 27 & 34.2 \\
& $41-60$ & 23 & 42.6 & 23 & 92.0 & 46 & 58.2 \\
& Over 60 & 4 & 7.4 & 2 & 8.0 & 6 & 7.6 \\
& Total & 54 & 100.0 & 25 & 100.0 & 79 & 100.0 \\
& Female & 37 & 68.5 & 23 & 92.0 & 60 & 75.9 \\
& Male & 17 & 31.5 & 2 & 8.0 & 19 & 24.1 \\
& Total & 54 & 100.0 & 25 & 100.0 & 79 & 100.0 \\
\hline
\end{tabular}

\subsection{Occupant Comfort between Two Hospital Groups}

The survey of this study posted ten questions to the participants concerning their perceptions of the comfort within their current workplace (Table 2). The respondents assessed each of the categories on a seven-point scale, from least comfortable ( $\mathrm{score}=1$ ) to most comfortable ( $\mathrm{score}=7$ ).

Mean values and the standard deviations for each comfort categories are shown in Table 2 for LEED and non-LEED-certified hospitals. All the means for LEED-certified hospitals were higher than neutral $(\mathrm{score}=4)$ while most of the means for non-LEED-certified hospitals were equal to or less than neutral. Only lighting and indoor natural settings were rated higher than neutral among non-LEED occupants. Noise and temperature were the categories rated lowest by the occupants from both hospital types comparing to other categories. However, occupants from LEED-certified hospitals rated these two categories significantly higher than those from conventional hospitals (see Table 2).

Mean difference tests were conducted and F-values were verified to confirm whether there was statistically significant difference between the responses from two occupant groups. The analytic software computed p-values for each question were shown in the last column of Table 2 . The p-values for all ten categories were less than 0.001 , which means the occupants from LEED and conventional hospitals differed significantly higher for all the examined comfort categories.

When the analysis conducted to examine these differences between groups depending on the indoor environmental quality elements and design elements, the biggest difference was found in "outdoor lounge" and the next biggest difference between two groups was in "materials and colors." Although there were significant differences between two groups in terms of "lighting," "noise," and "ventilation," more differences were found in design related elements applied in these target hospitals, which means the updated design elements of green hospitals play an important role in improving occupants' comfort. 
Table 2. Mean values and p-values for comfort categories between LEED and conventional hospital occupants

\begin{tabular}{|c|c|c|c|c|c|c|}
\hline Category & $\begin{array}{l}\text { Comfort } \\
\text { category }\end{array}$ & Items & LEED-certified & Conventional & F-Value & P-value \\
\hline \multirow{10}{*}{$\begin{array}{l}\text { Indoor } \\
\text { environmental } \\
\text { quality } \\
\text { elements }\end{array}$} & \multirow[t]{2}{*}{ Temperature } & Mean & 4.94 & 2.84 & 33.842 & $<0.001$ \\
\hline & & Std. deviation & 1.47 & 1.55 & & \\
\hline & \multirow[t]{2}{*}{ Humidity } & Mean & 5.81 & 3.60 & 46.723 & $<0.001$ \\
\hline & & Std. deviation & 1.12 & 1.73 & & \\
\hline & \multirow[t]{2}{*}{ Noise } & Mean & 5.54 & 3.16 & 55.991 & $<0.001$ \\
\hline & & Std. deviation & 1.15 & 1.63 & & \\
\hline & \multirow[t]{2}{*}{ Ventilation } & Mean & 5.72 & 3.44 & 47.929 & $<0.001$ \\
\hline & & Std. deviation & 1.19 & 1.69 & & \\
\hline & \multirow[t]{2}{*}{ Lighting } & Mean & 6.31 & 4.36 & 74.593 & $<0.001$ \\
\hline & & Std. deviation & 0.72 & 1.29 & & \\
\hline \multirow{10}{*}{$\begin{array}{l}\text { Design } \\
\text { elements }\end{array}$} & \multirow[t]{2}{*}{ Layout } & Mean & 5.72 & 3.92 & 33.739 & $<0.001$ \\
\hline & & Std. deviation & 1.20 & 1.44 & & \\
\hline & \multirow[t]{2}{*}{ Wayfinding } & Mean & 5.61 & 3.88 & 31.426 & $<0.001$ \\
\hline & & Std. deviation & 0.98 & 1.76 & & \\
\hline & Materials \& & Mean & 6.24 & 3.92 & 91.195 & $<0.001$ \\
\hline & colors & Std. deviation & 0.85 & 1.29 & & \\
\hline & Indoor natural & Mean & 6.07 & 4.76 & 16.675 & $<0.001$ \\
\hline & settings & Std. deviation & 0.99 & 1.88 & & \\
\hline & Outdoor & Mean & 6.20 & 2.92 & 95.479 & $<0.001$ \\
\hline & Lounge & Std. deviation & 1.19 & 1.75 & & \\
\hline
\end{tabular}

Note: $1=$ least comfortable to $7=$ most comfortable

\subsection{Occupant Satisfaction between Two Hospital Groups}

When the occupants' satisfaction was examined toward their workplace with seven questions, healthcare staff members working in LEED-certified hospitals showed higher satisfaction scores in all seven items. The results are presented in Table 3. These differences were verified by mean difference test. Results showed three questions - "happy to work", "adequate personal space", and "excellent to work compared to other hospitals"- had p-values less than 0.05 and two questions - "adequate safety and health standards" and "balance between work and personal life" - had p-values less than 0.001. All these five questions showed statistical difference between the respondents from two hospital groups. The other two questions included "like the job" and "department is well organized" had p-values higher than 0.05 , which indicated there was no significant difference in their satisfactions between the two groups. These findings strongly supported that occupants in the green hospital showed more positive opinions toward their work environments. 
Table 3. Means and p-values for each satisfaction question between LEED and conventional hospital occupants

\begin{tabular}{|c|c|c|c|c|c|}
\hline Satisfaction questions & Item & LEED-certified & Conventional & F-Value & P-value \\
\hline \multirow[t]{2}{*}{ Happy to work } & Mean & 6.43 & 6.00 & 4.032 & 0.048 \\
\hline & Std. deviation & 0.71 & 1.15 & & \\
\hline \multirow[t]{2}{*}{ Like the job } & Mean & 6.56 & 6.24 & 2.051 & 0.156 \\
\hline & Std. deviation & 0.71 & 1.23 & & \\
\hline Department is well & Mean & 5.96 & 5.92 & 0.028 & 0.868 \\
\hline organized & Std. deviation & 0.93 & 1.32 & & \\
\hline Adequate safety \& & Mean & 6.30 & 5.36 & 14.977 & 0.000 \\
\hline health standards & Std. deviation & 0.79 & 1.35 & & \\
\hline Adequate personal & Mean & 5.76 & 4.96 & 4.548 & 0.036 \\
\hline space & Std. deviation & 1.41 & 1.81 & & \\
\hline Balance between work & Mean & 6.11 & 4.72 & 20.808 & 0.000 \\
\hline and personal life & Std. deviation & 0.83 & 1.88 & & \\
\hline \multirow[t]{2}{*}{ Excellent to work } & Mean & 6.39 & 5.80 & 6.828 & 0.011 \\
\hline & Std. deviation & 0.85 & 1.08 & & \\
\hline
\end{tabular}

Note: $1=$ not at all satisfied to $7=$ strongly satisfied

\subsection{Occupants' Perceived Comfort and Overall Satisfaction}

According to the analysis of occupant satisfaction, a new variable -overall satisfaction- was computed by averaging the scores of the five relevant questions. Overall satisfaction was, then, used as satisfaction perception for all the discussions beyond this point.

Once it was confirmed there was statistical difference in the perception of comfort and satisfaction among the staffs between two hospital groups, it was important to identify which comfort categories influenced the overall satisfaction toward their workplace and which didn't. Pearson's correlational analysis was performed to test the correlations between each comfort category and the overall satisfaction. The computed p-values were shown in Table 4 for LEED-certified hospital occupants and Table 5 for conventional hospital occupants.

Table 4 shows the correlation between each comfort category and the satisfaction as well as between every two comfort categories for LEED-certified hospitals. The first line shows the correlation between each comfort category and overall satisfaction. Seven comfort categories from Table 4 including hospital layout, wayfinding, materials and colors, indoor natural settings, lighting, ventilation, and humidity showed higher correlation coefficient with significant p-values less than 0.05 which indicated positive strong correlation with overall satisfaction. On the other hand, noise, temperature, and outdoor lounge gave p-values higher than 0.05 , which indicated no significant correlation between these variables and overall satisfaction. This means, in LEED-certified hospitals, the perception toward the seven comfort categories influenced their satisfaction toward their workplace significantly. Among these seven comfort categories, four of them were design elements and three of them were indoor environmental quality elements, which indicated that occupant comfort in the LEED-certified hospital might be affected by not only green building features but also design features.

When the research team examined the correlations among ten elements, occupant comfort in wayfinding was significantly correlated with hospital layout $(r=.483, p<.001)$, which was an expected result. However, it was also significantly correlated with indoor natural settings $(r=.381, p<.005)$ and lighting $(r=.363, p<.01)$. These two elements in a green hospital seemed to help healthcare staffs find out their destinations within the building. Occupant comfort in temperature was strongly correlated with humidity $(r=.567, p<.001)$. The comfort levels for outdoor lounge was also strongly correlated with humidity $(r=.427, p<.005)$ and indoor natural settings $(r=.437, p<.001)$. 
Table 4. Pearson correlation coefficients between overall satisfaction and each comfort item for LEED-certified hospital occupants

\begin{tabular}{|c|c|c|c|c|c|c|c|c|c|c|c|}
\hline \multirow[t]{3}{*}{ Item } & \multirow{3}{*}{$\begin{array}{l}\text { Overall } \\
\text { Satisfaction }\end{array}$} & \multicolumn{5}{|c|}{ Indoor environmental quality elements } & \multicolumn{5}{|c|}{ Design elements } \\
\hline & & Tempera-ture & Humidity & Noise & Ventila-tion & Lighting & Layout & Way-finding & Materials & Indoor & Outdoor \\
\hline & & & & & & & & & $\&$ colors & $\begin{array}{l}\text { natural } \\
\text { settings }\end{array}$ & lounge \\
\hline \multicolumn{2}{|l|}{ Overall satisfaction } & .251 & $.340^{*}$ & .109 & $.531^{* * * *}$ & $.354^{* *}$ & $.532^{* * * *}$ & $.344^{*}$ & $.276^{*}$ & $.376^{* *}$ & .257 \\
\hline \multirow{5}{*}{$\begin{array}{l}\text { Indoor } \\
\text { environ-mental } \\
\text { quality elements }\end{array}$} & Tempera-ture & 1.000 & $.567^{* * * *}$ & .052 & $.315^{*}$ & $.336^{*}$ & .215 & .024 & -.050 & .159 & $.309^{*}$ \\
\hline & Humidity & $.567^{* * * *}$ & 1.000 & .242 & $.273^{*}$ & $.378^{* * *}$ & $.368^{* *}$ & .157 & .148 & $.269^{*}$ & $.427^{* * *}$ \\
\hline & Noise & .052 & .242 & 1.000 & $.375^{* *}$ & $.385^{* * *}$ & .097 & $.291^{*}$ & .117 & .114 & .154 \\
\hline & Ventila-tion & $.315^{*}$ & $.273^{*}$ & $.375^{* *}$ & 1.000 & $.434^{* * *}$ & .262 & .068 & .256 & .243 & .228 \\
\hline & Lighting & $.336^{*}$ & $.378^{* * *}$ & $.385^{* * *}$ & $.434^{* * *}$ & 1.000 & .189 & $.363^{* *}$ & $.461^{* * * *}$ & $.337^{*}$ & .254 \\
\hline \multirow[t]{10}{*}{ Design elements } & Hospital & .215 & $.368^{* *}$ & .097 & .262 & .189 & 1.000 & $.483^{* * * *}$ & .141 & $.319^{*}$ & .054 \\
\hline & Layout & & & & & & & & & & \\
\hline & Way-finding & .024 & .157 & $.291^{*}$ & .068 & $.363^{* *}$ & $.483^{* * * *}$ & 1.000 & $.275^{*}$ & $.381^{* * *}$ & .151 \\
\hline & Materials \& & -.050 & .148 & .117 & .256 & $.461^{* * * * *}$ & .141 & $.275^{*}$ & 1.000 & $.588^{* * * * *}$ & $.345^{*}$ \\
\hline & Colors & & & & & & & & & & \\
\hline & Indoor & .159 & $.269^{*}$ & .114 & .243 & $.337^{*}$ & $.319^{*}$ & $.381^{* * *}$ & $.588^{* * *}$ & 1.000 & $.437^{* * * *}$ \\
\hline & natural & & & & & & & & & & \\
\hline & settings & & & & & & & & & & \\
\hline & Outdoor & $.309^{*}$ & $.427^{* * *}$ & .154 & .228 & .254 & .054 & .151 & $.345^{*}$ & $.437^{* * * *}$ & 1.000 \\
\hline & lounge & & & & & & & & & & \\
\hline
\end{tabular}

Note: The number of "*" following the correlation coefficients indicates the p-value and is defined as follows:

$* \mathrm{p}<0.05 \quad * * \mathrm{p}<0.01 \quad * * * \mathrm{p}<0.005 \quad * * * *: \mathrm{p}<0.001$

Table 5, all ten comfort categories showed p-values higher than 0.05 with satisfaction which means all the comfort categories were not significantly correlated with overall satisfaction. This means, in non-LEED-certified hospitals, the perception of all ten investigated comfort categories didn't influence the perceived satisfaction toward their workplace. From Table 5, we concluded that all the comfort categories were rated mostly neutral by the staffs in the conventional, non-LEED-certified hospital. This might suggest that job satisfaction levels in the conventional hospital were less likely influenced by the building environmental characteristics.

In the conventional hospitals, temperature and humidity were significantly correlated with each other $(r=.784$, $p<.001)$, as Table 5 shows. Interestingly, wayfinding was more strongly correlated with materials and colors $(r$ $=.454, p<.05)$ and lighting $(r=.479, p<.05)$ rather than with hospital layout. This result indicated that the conventional hospitals selected in this study did not offer an appropriate layout that could help easy wayfinding for healthcare staffs working therein. Colors and materials of floors and walls or changes in lighting colors or fixtures in interiors seem to help occupants find their directions in conventional hospitals. 
Table 5. Pearson correlation coefficients between overall satisfaction and each comfort category for conventional hospital occupants

\begin{tabular}{|c|c|c|c|c|c|c|c|c|c|c|c|c|}
\hline \multirow[t]{3}{*}{ Item } & & \multirow{3}{*}{$\begin{array}{r}\text { Overall } \\
\text { satisfaction }\end{array}$} & \multicolumn{5}{|c|}{ Indoor environmental quality elements } & \multicolumn{5}{|c|}{ Design elements } \\
\hline & & & Temp- & Humid & Noise & Ventila & Lighting & Layout & Way-fin & Materials & Indoor & Outdoor \\
\hline & & & erature & -ity & & -tion & & & ding & $\&$ colors & $\begin{array}{l}\text { natural } \\
\text { settings }\end{array}$ & lounge \\
\hline \multicolumn{2}{|c|}{ Overall satisfaction } & 1.000 & .118 & .246 & -.281 & .12 & .033 & .112 & -.171 & -.13 & .321 & .213 \\
\hline \multirow{7}{*}{$\begin{array}{l}\text { Indoor } \\
\text { environm } \\
\text { ental } \\
\text { quality } \\
\text { elements }\end{array}$} & Temper- & .118 & 1.000 & $.784^{* * * *}$ & $.475^{*}$ & $.556^{* *}$ & .386 & .443 & $.497^{*}$ & $.497^{*}$ & -.043 & .164 \\
\hline & ature & & & & & * & & & & & & \\
\hline & Humidity & .246 & $.784^{\text {*edek }}$ & 1.000 & .32 & $.677^{* * * * *}$ & $.460^{*}$ & $.404^{*}$ & .284 & .321 & -.044 & .318 \\
\hline & Noise & -.281 & $.475^{*}$ & .32 & 1.000 & .323 & $.469^{*}$ & .273 & $.516^{* *}$ & .484 & .013 & .034 \\
\hline & Ventilati & .12 & $.556^{* *}$ & $.677^{* * * *}$ & .323 & 1.000 & $.577^{* * *}$ & .29 & $.425^{*}$ & .17 & .153 & .308 \\
\hline & on & & $*$ & & & & & & & & & \\
\hline & Lighting & .033 & .386 & $.46^{*}$ & $.469^{*}$ & $.577^{* * *}$ & 1.000 & -.051 & $.479^{*}$ & .32 & .21 & .087 \\
\hline \multirow{11}{*}{$\begin{array}{l}\text { Design } \\
\text { elements }\end{array}$} & Hospital & .112 & $.443^{*}$ & .404 & .273 & .29 & -.051 & 1.000 & .357 & .176 & .07 & .278 \\
\hline & Layout & & & & & & & & & & & \\
\hline & Way-fin & -.171 & $.497^{*}$ & .284 & $.516^{* *}$ & $.425^{*}$ & $.479^{*}$ & .357 & 1.000 & $.454^{*}$ & .381 & .078 \\
\hline & ding & & & & & & & & & & & \\
\hline & Materials & -.13 & .37 & .321 & $.484^{*}$ & .17 & .32 & .176 & $.454^{*}$ & 1.000 & -.112 & .2 \\
\hline & $\&$ Colors & & & & & & & & & & & \\
\hline & Indoor & .321 & -.043 & -.044 & .013 & .153 & .21 & .07 & .381 & -.112 & 1.000 & .133 \\
\hline & natural & & & & & & & & & & & \\
\hline & settings & & & & & & & & & & & \\
\hline & Outdoor & .213 & .164 & .318 & .034 & .308 & .087 & .278 & .078 & .2 & .133 & 1.000 \\
\hline & lounge & & & & & & & & & & & \\
\hline
\end{tabular}

Note: The number of "*” following the correlation coefficients indicates the p-value and is defined as follows:

$* \mathrm{p}<0.05 \quad * * \mathrm{p}<0.01 * * * \mathrm{p}<0.005$

$* * * * \mathrm{p}<0.001$ In the conventional hospital, as presented

in

\subsection{Effects of Perceived Comfort Categories on Overall Satisfaction in Healthcare Environments}

As revealed earlier, seven out of ten comfort categories were significantly correlated with satisfaction among the respondents from LEED-certified hospitals. Among these seven comfort categories that were hospital layout, wayfinding, materials and colors, and indoor natural settings from hospital design elements, and lighting, ventilation, and humidity from indoor environmental quality elements, the next analysis identified which category contributed more significantly toward occupants' overall satisfaction in the healthcare environments. In order to do this, simple linear regression was carried out to determine if there was any linear relationship between each comfort category and the overall satisfaction (Table 6). The regression coefficient indicates the degree and the direction (positive or negative) of the correlation. P-values were also computed which indicated whether the coefficient significantly differed from zero.

Because the sample size for the conventional hospital was small, the research team did not compare the regressional models between the two hospital groups. The regressional models for all responses were examined. This simple regression analysis aimed to verify explanatory variables that affected healthcare staffs' satisfaction with their workplace in general. The linear regression results verified that lighting, ventilation, hospital layout, and wayfinding were the top four effective comfort category more affecting occupant overall satisfaction in 
healthcare environments.

In other words, these four elements affect occupants' satisfaction with their healthcare environments in both green and conventional healthcare environments. The other comfort categories such as indoor natural settings, materials and colors, and humidity also showed significant contribution toward overall satisfaction as well. The research team expected a significant contribution of outdoor lounge toward overall satisfaction, but the result showed that there was a weak correlation between these two. Based on a short site observation after the survey, the research team concluded that the visibility of the outdoor lounge should improve to attract more staff member or facility users to visit.

Table 6. Simple linear regression between overall satisfaction and comfort categories

\begin{tabular}{llrrr}
\hline Categories & Independent Variable & Coefficient & Constant & \multicolumn{1}{c}{ P-value } \\
\hline Indoor & Temperature & 0.101 & 5.713 & 0.068 \\
environmental & Humidity & 0.181 & 5.159 & 0.012 \\
quality elements & Noise & 0.057 & 5.901 & 0.434 \\
& Ventilation & 0.266 & 4.690 & 0.000 \\
& Lighting & 0.292 & 4.371 & 0.009 \\
Design elements & Hospital layout & 0.263 & 4.709 & 0.000 \\
& Wayfinding & 0.209 & 5.040 & 0.011 \\
& Materials \& colors & 0.194 & 5.002 & 0.044 \\
& Indoor natural settings & 0.227 & 4.838 & 0.005 \\
& Outdoor lounge & 0.129 & 5.414 & 0.060 \\
\hline
\end{tabular}

Note: Dependent variable $=$ Overall satisfaction

\section{Discussion}

\subsection{Staff Perception of Comfort}

During this study, the research team measured ten aspects of comfort in healthcare work environment and found that for all of the aspects, the healthcare staffs from LEED-certified hospitals rated higher or felt more comfortable than those staff from non-LEED-certified hospitals. Although actual indoor environmental conditions such as temperature, humidity, and indoor air quality were not measured, the occupants' perceptions of comfort and satisfaction significantly support the hypothesis that green hospitals can outperform conventional buildings in terms of design elements (i.e., wayfinding, layout, serenity), and indoor environmental quality elements such as lighting, ventilation, acoustics and humidity.

\subsubsection{Indoor Environmental Quality Elements}

In the LEED-certified hospitals, the comfort for lighting was scored 6.31 in average, which was the highest among ten comfort aspects included in this study. The introduction of more natural light and the green features of the artificial lighting design not only reduced the energy consumption but were also favored by the staff because they were perceived to increase visual comfort and reduce glare, which could have positively affected the ambience in interior spaces. The comfort of lighting levels also improved staff effectiveness while performing critical tasks such as dispensing prescribed medications. It's interesting to see Table 4 that the perception toward lighting was also correlated to noise, ventilation, temperature and humidity. This seems attributed to "spirit lifting," as suggested by Boyce (Boyce, 1998). High quality lighting can eliminate distractions and discomforts, and adds an aesthetic element which may promote emotional functioning and serve as a buffer to discomforts or stresses. The average score of lighting for the non-LEED-certified hospital in this study was 4.36, one of the highest among the ten categories; although it was significantly lower than that for LEED-certified hospitals. Lighting in the conventional hospital may not offend or distract the staffs, but apparently fails to lift the human spirit.

In the LEED-certified hospitals, noise had an average score of 5.54, one of the lowest rated categories. However, it was still rated significantly higher than neutral $(=4.0)$. As discussed in many studies in literature, higher sound levels were perceived as stressful. Hospitals usually are excessively noisy due to numerous noise sources 
including alarms, moving bedrails, telephones, trolleys, pneumatic tubes etc. In addition, the sound-reflecting surfaces as well as badly designed layout can cause noise to propagate considerable distances, traveling down corridors and into staff offices (Ulrich, 2000). Generally several environmental interventions could be used to reduce the noise level including installing high-performance sound absorbing ceilings, adopting noiseless systems, and providing single-bed rather than multi-bed rooms. In addition to lighting and wayfinding discussed previously, noise was also found to correlate with ventilation. LEED-certified buildings were found to have worse noise level due to open plan offices and spaces than non-LEED buildings in literature (De Salis et al., 2002; Edwards, 2006; Lee \& Guerin, 2009; Swift et al., 2008). However, this is obviously not the case in the LEED-certified hospitals studied. Comparing to the average score of 3.16 in the non-LEED-certified hospital, the performance of the LEED-certified hospitals were perceived significantly better by the staffs.

For ventilation, the staffs in LEED-certified hospitals rated an average score of 5.72. Ventilation was correlated significantly with temperature and humidity which suggests adequate ventilation could be critical for maintaining good indoor environmental quality including temperature and humidity. In the non-LEED-certified hospital, the average score for ventilation was only 3.44, which is lower than neutral and significantly lower than that of LEED-certified hospitals.

In LEED-certified hospitals, comfort for the temperature had an average score of 4.94, the lowest among the ten categories, indicating the staffs felt least comfortable in temperature compared to other categories. However, the score was still higher than neutral and significantly higher than that from the non-LEED-certified hospital, which was 2.84 in this case. Temperature was also found to strongly correlate with humidity. This is not surprising because it has been found that the perception of temperature is affected by the relative humidity (Balaras et al., 2007; Wolkoff et al., 2007). Considering occupant opinions on temperature of this study, healthcare environments should make an effort to improve thermal comfort for staffs. Lower thermal comfort seemed to result in lower satisfaction with their working environments. Similarly, humidity in LEED-certified hospitals (5.81) was rated significantly higher than that from the conventional hospital. In the conventional hospital, humidity had an average of 3.60 , which was worse than neutral.

\subsubsection{Design Elements}

In the LEED-certified hospitals, hospital layout was scored 5.72 in average. As suggested by a few studies, the type of unit layout (radial, single corridor, double corridor) influences the amount of walking among nursing staff, and time saved from walking was translated into reduced stress and fatigue (Shepley, 2002; Trites et al., 1970). Better designed layout improves work flow and reduces medical errors, which again reduces work-related stress (Pierce et al, 1990). In Table 4, the perception towards hospital layout was strongly correlated with wayfinding and indoor natural settings in the LEED-certified hospitals. The LEED-certified hospitals had significantly considered hospital layout and wayfinding systems in addition to improving indoor environmental quality, and thus may have improved overall occupants' satisfaction levels. The LEED-certified hospitals had also provided more opportunities of encountering indoor natural settings. In the conventional hospital, hospital layout had been rated an average score of 3.92, close to neutral. This difference between two groups indicates a significant improvement on the layout design in the LEED-certified hospitals which were appreciated by the staff respondents.

In the LEED-certified hospitals, comfort for the wayfinding had an average score of 5.61. The problems of wayfinding system in general hospitals have been found to be costly and stressful by previous studies and have particular impacts on outpatients and visitors, who are more unfamiliar with the hospital. The stress to the staffs comes from the direction for the visitors giving by them other than information staff, which occupied a significant amount of time (Ulrich et al, 2008).

Other than the layout design discussed previously, the perception of wayfinding by the staffs also correlated strongly with their perceptions of materials and colors, lighting, noise, and indoor natural settings as shown in Table 4. Materials and colors and indoor natural settings could have added some coordinated elements in addition to the signage for wayfinding. For example, changes in flooring material can more clearly convey the message that the individual is moving from one area into another. Better lighting can be expected to improve the visibility of the signage to the visitors and patients. Lower noise levels can contribute to reducing the stress for both visitors and staff members. Increasing the chances of finding their destinations correctly using the wayfinding system can also improve the level of comfort. These elements could have reduced the need for staff members to answering wayfinding questions raised from visitors and patients which helps to reduce the stress for them. The average score for wayfinding in the conventional hospitals was 3.88, a little lower than neutral $(=4.0)$, indicating a slightly negative perception toward wayfinding system in the conventional non-LEED-certified 
hospital.

In the LEED-certified hospitals, materials and colors had an average score of 6.20. The use of low toxic and low emission materials may have significantly reduced indoor pollutant loads to thus improve indoor air quality, which can influence the indoor environmental quality. The color schemes used for interior design and the colors introduced by natural plants may have also helped the healthcare staffs recover from work environment stress. This could be the reason of strong correlation between the perception of materials and colors and outdoor lounge. The average score of materials and colors was 3.92 for non-LEED-certified hospitals indicating a nearly neutral perception.

The indoor natural settings was rated 6.07 in average in LEED-certified hospitals. Various populations in many studies examined in different types of spaces have shown strong evidence that even fairly brief encounters with real or simulated nature settings can elicit significant recovery from stress (Parsons, 2000). The result obtained in this study confirmed the same observation for the healthcare staffs. The correlation between indoor natural settings and outdoor lounge could be easily understood since they were very similar in nature. In the non-LEED-certified hospital, indoor natural settings had an average score of 4.76, which was the highest among the ten categories for the non-LEED-certified hospital. However, the score from the LEED-certified hospitals studied is significantly higher. The staff comfort level of outdoor lounge in the conventional hospital was very low (2.92), while the comfort level in the LEED-certified hospitals was 6.20. This item has the biggest difference in the mean comfort values between the two hospital groups. The effects of designing outdoor lounges in green hospitals seemed very positive while there was very limited outdoor lounge space available in the conventional hospital.

\subsubsection{Staff Perception of Overall Satisfaction toward the Workplace}

As shown in Table 4 and 5, the staff perception of overall satisfaction was statistically higher in the LEED-certified hospitals in this study than that in the conventional hospital. This suggests that the green hospital design may have more positively resulted in higher levels of overall satisfaction.

Although the perceptions of all the ten comfort categories in this study showed significant difference between two groups of staffs in LEED- or non-LEED-certified hospitals, only seven of them (i.e., hospital layout, wayfinding, materials and colors, lighting, ventilation, indoor natural settings, and humidity) showed significant correlation with satisfaction among the staffs working in LEED-certified hospitals. Noise, temperature and outdoor lounge were the three categories that showed no correlation with overall satisfaction. The perception of the other seven categories directly influenced the staff satisfaction. They were ranked based on the linear regression models from higher to lower in the regression coefficient values as: lighting $>$ ventilation $>$ hospital layout $>$ indoor natural settings $>$ wayfinding $>$ materials and colors $>$ humidity.

\section{Conclusion and Implications}

This research examined significant relationships between healthcare staff members' satisfactions and important environmental elements in both green and conventional healthcare environments. Based on the overall results from an empirical study targeting two groups of hospitals, the research team conclude that the green features implemented in LEED healthcare facilities may have positive effect on healthcare staffs' perceptions of comfort and satisfaction while they are working in those indoor environments. For all the categories studied, staffs from the LEED-certified hospitals examined rated "comfortable" while those from the conventional hospital examined rated mainly neutral.

The research findings of this study suggest key design implication ideas for future healthcare environments. In a subject LEED-certified hospital, radial layout design is adopted which is known to reduce the amount of walking by the staffs. In addition, the radial design also helps to maximize the introduction of natural light into most patient rooms and offices. The better perception of the layout design by the staffs from the LEED-certified hospitals suggests that the radial layout design is beneficial and should be recommended in the future design.

Better wayfinding and signing system could reduce stress possibly because of fewer questions from the patients and visitors about the route. In the LEED-certified hospitals studied, the floor materials or the color of the carpets were different in different areas. This added some coordinated elements in addition to the signage for wayfinding. The carpet patterns were the same throughout the entire hospital in the non-LEED hospital studied. The difference in the perception of the wayfinding system suggests that future hospital design should consider using different floor materials and/or floor colors to aid wayfinding.

The indoor environments in the LEED-certified hospitals studied were rated as significantly better and as reflected by the higher perception of the comfort. The lighting design in the LEED-certified hospitals maximized 
the introduction of natural light. This not only saved energy, but also helped to reduce stress. In contrast, in the non-LEED-certified hospital studied, very limited natural lighting was available in the building. In one of the two subject LEED-certified hospitals, a filtration system had been installed in the ventilation system to filter $80 \%$ the particles smaller than $1 \mu \mathrm{m}$. In both of the LEED-certified hospitals for this study, materials and chemicals with very low emission were used. All these features significantly improved the indoor air quality and were greatly appreciated by the staffs working in the environment. In future hospital design, it would be beneficial to incorporate these features which help to provide healthier indoor environments.

The LEED-certified hospitals selected for this study had healing gardens which were not found in the conventional hospital studied. Healing garden not only helped the recovery of the patients but also provided an outdoor for the staffs to relax and to connect with the nature, which significantly reduced the stress and fatigue of the staffs. As indicated by the results from this study, healing gardens should be incorporated in future hospital design when possible.

Although many indoor environmental aspects were satisfied in these green hospitals, it should be clearly indicated that the thermal comfort level was still low in the LEED-certified hospitals. Because low comfort in indoor temperature and humidity can cause lower satisfaction with their working environments, these two aspects should be carefully managed for bettering indoor environmental quality in healthcare facilities to improve more the staffs' comfort and satisfaction with their working environment. These considerations will ultimately bring positive health outcomes for patients.

\section{References}

Bayo, M. V., \& Garcia, A. M. (1995). Noise levels in an urban hospital and workers subjective responses, Archives of Environmental Health, 50(3), 247-251. http://dx.doi.org/10.1080/00039896.1995.9940395

Billeter-Koponen, S., \& Freden, L. (2005). Long-term stress, burnout and patient-nurse relations: qualitative interview study about nurses' experiences. Scandinavian Journal of Caring Sciences, 19(1), 20-27. http://dx.doi.org/10.1111/j.1471-6712.2005.00318.x

Blomkvist, V., \& Eriksen, C. A. (2005). Acoustics and psychosocial environment in coronary intensive care. Occupational and Environmental Medicine, 62(3), 1-8. http://dx.doi.org/10.1136/oem.2004.017632

Bordass, W. (2000). Performance spaces. The Architects' Journal, 2, 56-57.

Boyce, P. (1998). Lighting quality: the unanswered questions. Paper presented at the CIE Symposium on Lighting Quality, Ottawa, Canada.

Buchanan, T. L., Barker, K. N., Gibson, J. T., Jiang, B. C., \& Pearson, R. E. (1991). Illumination and errors in dispensing. American Journal of Hospital Pharmacy, 48(10), 2137-2145.

Collins, B. L. (1995). Windows and people: a literature survey. US National Bureau of Standards Building Science Series, Washington DC.

Cooper, M. C., \& Barnes, M. (1995). Gardens in healthcare facilities: Uses, therapeutic benefits, and design recommendations. The Center for Health Design, California.

De Salis, M., Oldham, D. J., \& Sharples, S. (2002). Noise control strategies for naturally ventilated buildings. Building and Environment, 37(5), 471-484. http://dx.doi.org/10.1016/S0360-1323(01)00047-6

Edwards, B. (2006). Benefits of green offices in the UK. Sustainable Development, 14, 190-204. http://dx.doi.org/10.1002/sd.263

Galasiu, A. D., \& Veitch, J. A. (2006). Occupant preferences and satisfaction with the luminous environment and control systems in daylit offices: A literature review. Energy and Buildings, 38(7), 728-742. http://dx.doi.org/10.1016/j.enbuild.2006.03.001

Gastle, N. (2006). An instrument to measure job satisfaction of nursing home administrators. BMC Medical Research Methodology, 6(47), 1-11.

Haung, Y. (2009). Impact of green building design on healthcare occupants: With a focus on healthcare staff. (Unpublished master thesis). Interior Design, Michigan State University, East Lansing, Michigan.

Heerwagen, J. H. (2000). Green buildings, organizational success, and occupant productivity. Building Research and Information, 28(5), 353-367. http://dx.doi.org/10.1080/096132100418500

Heerwagen, J. H., \& Orians, G. H. (1986). Adaptations to windowlessness: A study of the use of visual decor in windowed and windowless offices. Environment and Behavior, 18(5), 623-630. 
http://dx.doi.org/10.1177/0013916586185003

Hua, Y., Oswald, A., \& Yang, X. D. (2010). Effectiveness of daylighting design and occupant visual satisfaction in a LEED gold laboratory building. Building and Environment, 46(1), 54-64. http://dx.doi.org/10.1016/j.buildenv.2010.06.016

Hummelgaard, J., Juhl, P., Saebjornsson, K. O., Clausen, G., Toftum, J., \& Langkilde, G. (2007). Indoor air quality and occupant satisfaction in five mechanically and four naturally ventilated open-plan office buildings. Building and Environment, 42(12), 4051-4058. http://dx.doi.org/10.1016/j.buildenv.2006.07.042

Jensen, W., Fischer, B., Wentz, T., \& Camara, G. (2008). A proposed LEED standard for indoor acoustical quality. Journal of Green Building, 3(1), 93-101. http://dx.doi.org/10.3992/jgb.3.1.91

Jiang, S., Huang, L., Chen, X., Wang, J., Wu, W., \& Yin, S. (2003). Ventilation of wards and nosocomial outbreak of severe acute respiratory syndrome among healthcare workers. Chinese Medical Journal, 116(9), 1293-1297.

Krogstad, A. L., \& Jorulf, L. (1991). A prospective study of indoor climate problems at different temperatures in offices. Goteborg, Sweden: Volvo Truck Corp.

Leather, P., Pyrgas, M., Beale, D., \& Lawrence, C. (1998). Windows in the workplace: Sunlight, view, and $\begin{array}{lllll}\text { occupational stress. Environment and 30havior, } & \text { 362. }\end{array}$ http://dx.doi.org/10.1177/001391659803000601

Lee, Y. S. (2011). Lighting quality and acoustic quality in LEED-certified buildings using occupant evaluation. Journal of Green Building, 6(2), 139-155. http://dx.doi.org/10.3992/jgb.6.2.139

Lee, Y. S., \& Kim, S. K. (2008). Indoor environmental quality in LEED-certified buildings in the U.S. Journal of Asian Architecture and Building Engineering, 7(2), 293-300. http://dx.doi.org/10.3130/jaabe.7.293

Lee, Y. S., \& Guerin, D. A. (2009). Indoor environmental quality related to occupant satisfaction and performance in leed-certified buildings. Indoor and Built Environment, 18(4), 293-300. http://dx.doi.org/10.1177/1420326X09105455

Menzies, D., Fanning, A., Yuan, L., \& FitzGerald, J. M. (2000). Hospital ventilation and risk for tuberculosis infection in Canadian health care workers. Annals of Internal Medicine, 133(10), 779-789. http://dx.doi.org/10.7326/0003-4819-133-10-200011210-00010

National Institute of Building Sciences. (2010). Sustainable. Retrieved May 1, 2011, from http://www.wbdg.org/design/sustainable.php

Norbeck, J. S. (1985). Perceived job stress, job satisfaction, and psychological symptoms in critical care nursing. Research in Nursing \& Health, 8(3), 253-259. http://dx.doi.org/10.1002/nur.4770080307

Ozdemir, A. (2010). The effect of window views' openness and naturalness on the perception of rooms' spaciousness and brightness: A visual preference study. Scientific Research and Essays, 5(16), 2275-2287.

Paul, W. L., \& Taylor, P. A. (2008). A comparison of occupant comfort and satisfaction between a green building and a conventional building. Building and Environment, 43, 1858-1870. http://dx.doi.org/10.1016/j.buildenv.2007.11.006

Pierce, R. A., Rogers, E. M., Sharp, M. H., \& Musulin, M. (1990). Outpatient pharmacy redesign to improve work flow, waiting time, and patient satisfaction. American Journal of Hospital Pharmacy, 47(2), 351-356.

Roulet, C. A., Johner, N., Foradini, F., Bluyssen, P., Cox, C., \& Fernandes, E. D. (2006). Perceived health and comfort in relation to energy use and building characteristics. Building Research and Information, 34(5), 467-474. http://dx.doi.org/10.1080/09613210600822279

Scully, R. (1980). Stress in the nurse. American Journal of Nursing, 80(5), 911-915. http://dx.doi.org/10.2307/3470014

Sharma, A., Sharp, D. M., Walker, L. G., \& Monson, J. (2008). Stress and burnout among colorectal surgeons and colorectal nurse specialists working in the national health service. Colorectal Disease, 10(4), 397-406. http://dx.doi.org/10.1111/j.1463-1318.2007.01338.x

Simonson, C. J., Salonvaara, M., \& Ojanen, T. (2001). The effect of structures on indoor humidity: Possibility to improve comfort and perceived air quality. Indoor Air, 12(4), 243-251. http://dx.doi.org/10.1034/j.1600-0668.2002.01128.x

Smedbold, H., Catrine, A., Unimed, S., Nilsen, A., Norback, D., \& Hilt, D. (2002). Relationships between indoor 
environments and nasal inflammation in nursing personnel. Archives of Environmental Health, 57(2), 155-161. http://dx.doi.org/10.1080/00039890209602930

Sundstrom, E., Town, J. P., Rice, R. W., Osborn, D. P., \& Brill, M. (1994). Office noise, satisfaction, and performance. Environment and Behavior, 26(2), 195-222. http://dx.doi.org/10.1177/001391659402600204

Swift, P. B., \& Stead, M. J. (2008). Tall building acoustics and the challenges of sustainability. Structural Design of Tall and Special Buildings, 17(5), 977-987. http://dx.doi.org/10.1002/tal.481

Topf, M., \& Dillon, E. (1988). Noise-induced stress as a predictor of burnout in critical care nurses. Heart Lung, 17(5), 567-574.

Trites, D. K., Galbraith, F. D., Sturdavant, M., \& Leckwart, J. F. (1970). Influence of nursing unit design on activities and subjective feelings of nursing personnel. Environment and Behavior, 2(3), 303-334. http://dx.doi.org/10.1177/001391657000200304

Ulrich, R. S., Zimring, C., Zhu, X. M., DuBose, J., Seo, H. B., \& Choi, Y. S. (2008). A review of the research literature on evidence-based healthcare design. Health Environments Research \& Design Journal, 1(3), 61-125.

Ulrich, R. S. (2000). Effects of healthcare environmental design on medical outcomes. Proceedings of Design and Health World Conference, 2000.

US Green Building Council. (2014). LEED for Healthcare Projects. Retrieved September 1, 2014, from $\mathrm{http}: / /$ www.usgbc.org/projects/healthcare

US Green Building Council. (2009). USGBC History. Retrieved September 1, 2014, from http://www.usgbc.org/about/history

US Green Building Council. (2009). LEED rating systems - LEED for healthcare. Retrieved March 1, 2012, from http://www.usgbc.org

US Green Building Council. (2012). What LEED is. Retrieved April 6, 2012, from http://www.usgbc.org/DisplayPage.aspx?CMSPageID=1988

US Green Building Council Chicago Chapter. (2009). Regional green building green building case study project: A post-occupancy study of LEED projects in Illinois 2009. Retrieved January 10, 2009, from http://www.cnt.org/repository/Regional-Green-Building-Case-Study.pdf

Veitch, J. A., \& Newsham, G. R. (1998). Lighting quality and energy - efficiency effects on task performance, mood, health, satisfaction, and comfort. Journal of the Illuminating Engineering Society, 27(1), 107.

Xie, H., Gan, X. A., \& Ma, F. (2009). Field study of thermal comfort and indoor air quality in gymnasium. Journal of Central South University of Technology, 16, 48-54.

Zhang, Y. F., \& Altan, H. (2011). A comparison of the occupant comfort in a conventional high-rise office block and a comporary environmentally-concerned building. Building and Environment, 46(2), 535-545. http://dx.doi.org/10.1016/j.buildenv.2010.09.001

\section{Copyrights}

Copyright for this article is retained by the author(s), with first publication rights granted to the journal.

This is an open-access article distributed under the terms and conditions of the Creative Commons Attribution license (http://creativecommons.org/licenses/by/3.0/). 